\title{
RESEARCH
}

Open Access

\section{Neoadjuvant chemotherapy followed by cytoreductive surgery and hyperthermic intraperitoneal chemotherapy for colorectal cancer: a feasibility and safety study}

M. Leimkühler ${ }^{1 \dagger}$, P. H. J. Hemmer ${ }^{1 * \dagger}$, A. K. L. Reyners ${ }^{2}$, D. J. A. de Groot ${ }^{2}$, R. J. van Ginkel ${ }^{1}$, L. B. Been', G. H. de Bock ${ }^{3}$ and B. L. van Leeuwen ${ }^{1 *}$

\begin{abstract}
Background: Standard treatment for colorectal peritoneal carcinomatosis typically involves cytoreductive surgery, hyperthermic intraperitoneal chemotherapy (HIPEC), and if possible, postoperative adjuvant chemotherapy. However, a substantial percentage of patients never receive adjuvant chemotherapy because of postoperative complications. Neoadjuvant chemotherapy could be beneficial in this setting, so we assessed its feasibility and safety when used before cytoreductive surgery and HIPEC.
\end{abstract}

Methods: In this non-randomized, single-center, observational feasibility study, patients were scheduled to receive six cycles of capecitabine and oxaliplatin before cytoreductive surgery and HIPEC. Computed tomography was performed after the third and sixth chemotherapy cycles to evaluate tumor response, and patients underwent cytoreductive surgery and HIPEC if there were no pulmonary and/or hepatic metastases. Postoperative complications, graded according to the Clavien-Dindo classification, were compared with those of a historic control group that received postoperative adjuvant chemotherapy.

Results: Of the 14 patients included in the study, 4 and 3 had to terminate neoadjuvant chemotherapy early because of toxicity and tumor progression, respectively. Cytoreductive surgery and HIPEC were performed in eight patients, and the timing and severity of complications were comparable to those of patients in the historic control group treated without neoadjuvant chemotherapy.

Conclusion: Patients with peritoneal metastases due to colorectal carcinoma can be treated safely with neoadjuvant chemotherapy before definitive therapy with cytoreductive surgery and HIPEC.

Trial registration number: NTR 3905, registered on 20th march, 2013, http://www.trialregister.n//trialreg/admin/ rctview.asp?TC=3905

Keywords: Neoadjuvant chemotherapy, HIPEC, Colorectal cancer, Peritoneal carcinomatosis

\footnotetext{
* Correspondence: p.h.j.hemmer@umcg.nl; b.l.van.leeuwen@umcg.nl

${ }^{\dagger}$ M. Leimkühler and P. H. J. Hemmer contributed equally to this work.

${ }^{1}$ Department of Surgery, University of Groningen, University Medical Center

Groningen, Hanzeplein 1, 9713GZ, Groningen, The Netherlands

Full list of author information is available at the end of the article
}

(c) The Author(s). 2019 Open Access This article is distributed under the terms of the Creative Commons Attribution 4.0 International License (http://creativecommons.org/licenses/by/4.0/), which permits unrestricted use, distribution, and 


\section{Background}

Peritoneal carcinomatosis is common in patients with colorectal cancer, occurring in $5-10 \%$ of those presenting with synchronous peritoneal metastases and $20-50 \%$ of those presenting with metachronous peritoneal metastases [1]. If left untreated, the median patient survival of this group is 3-9 months [2]. Therefore, peritoneal carcinomatosis has long been considered an incurable disease [3], with palliative treatment extending median progressionfree survival to just 6-12 months [4-6]. However, recent developments in systemic treatment have increased the 2 -year survival of patients from approximately $0 \%$ in 2000 to $10-16 \%$ in 2014 [6-8].

In recent years, many institutions started treating patients with cytoreductive surgery (CRS) and hyperthermia intraperitoneal chemotherapy (HIPEC). A 5-year survival between 33 and $58 \%$ has been described in patients with colorectal carcinoma undergoing CRS plus HIPEC [9-11]. Because of this survival benefit, CRS plus HIPEC is considered the treatment of choice for patients with low-volume, low-grade peritoneal disease without systemic dissemination [3]. Since 2006, systemic adjuvant chemotherapy has been the logical treatment for preventing hematogenous and lymphogenous spread. However, the high postoperative complication rate following CRS and HIPEC, which has ranged from 23 to $66 \%$ [2, 7, 12-15], can leave many patients ineligible for adjuvant therapy, and no studies have shown evidence of survival benefit for this approach in patients with peritoneal carcinomatosis. Nevertheless, it has also been shown that neoadjuvant chemotherapy confers survival benefits in other tumors [16-19], and on this basis, we thought that it could be used before CRS and HIPEC in patients with colorectal cancer. In this way, it might even help to reduce tumor load and lessen the extent of surgery. A possible disadvantage, however, might be that neoadjuvant chemotherapy could negatively affect the postoperative complication rate. At the time of writing, we could identify no prospective data on the efficacy of neoadjuvant systemic treatment for this indication.

We conducted this feasibility study as a prequel to a larger prospective multicenter study of the efficacy of neoadjuvant systemic treatment in patients with peritoneal carcinomatosis due to colorectal cancer. The primary aim was to determine whether neoadjuvant chemotherapy influenced postoperative complication and mortality rates after CRS and HIPEC.

\section{Methods}

We conducted a non-randomized, single-center, observational feasibility study from April 2013 to July 2015 at the University Medical Center Groningen (UMCG), which is a referral center for HIPEC, serving 1.6 million inhabitants. A historical control cohort of patients treated with standard CRS and HIPEC, but without neoadjuvant chemotherapy, served as a reference population (20). The study was conducted in accordance with the Declaration of Helsinki and approved by the Medical Ethics Committee of the UMCG and was registered in the Dutch trial registry (NTR 3905).

\section{Patients}

Patients were recruited from the UMCG if they had peritoneal carcinomatosis of colorectal origin diagnosed by computed tomography (CT), diagnostic laparoscopy, or laparotomy. All diagnoses were confirmed by pathological examination. The following eligibility criteria were applied: World Health Organization (WHO) performance score of 0 or 1 , adequate bone marrow function (platelets $>100 \times 10^{9}$, neutrophils $>1.5 \times 10^{9}$ ), and adequate renal function (creatinine clearance $>50 \mathrm{~mL} / \mathrm{min}$ ).

The main exclusion criterion in the experimental group was prior treatment with adjuvant systemic chemotherapy within 12 months of the study. Patients were also excluded if they had a history of other malignancies (except basal cell carcinoma) or advanced liver disease (bilirubin $>34 \mu \mathrm{mol} / \mathrm{L}$ and/or an international normalized ratio $>1.7$ ). Finally, we excluded patients with liver and/or extra-abdominal metastases or neurotoxicity above grade 1 according to The Common Terminology Criteria for Adverse Events (Version 4.0) [20]. All included patients of the experimental group provided a written informed consent.

The historic reference population consisted of patients with peritoneal carcinomatosis of colorectal origin who were treated at the UMCG between 2006 and 2015 [21]. This reference population included 88 patients who received standard treatment, consisting of CRS and HIPEC, followed by adjuvant chemotherapy. We only included patients with a peritoneal cancer index (PCI) less than 20, because only this group has been shown to benefit from HIPEC. Dutch law does not require informed consent to use anonymized patient data for treatment evaluation.

\section{Standard treatment}

Standard treatment involves CRS plus HIPEC followed by cytoreductive surgery [22]. During surgery, all macroscopic lesions were removed, before intraperitoneal mitomycin $C$ was given at a dose of $35 \mathrm{mg} / \mathrm{m}^{2}$ over $90 \mathrm{~min}$. This chemotherapy was administered in three doses, with half given at the start of perfusion, one-quarter after $30 \mathrm{~min}$, and one-quarter after $60 \mathrm{~min}$; thereafter, perfusion continued for $30 \mathrm{~min}$ [23].

\section{Experimental treatment}

The experimental protocol involved giving neoadjuvant chemotherapy before CRS and HIPEC. Patients enrolled 
to this protocol were scheduled to receive six cycles of capecitabine $\left(1000 \mathrm{mg} / \mathrm{m}^{2}\right)$ and oxaliplatin $\left(130 \mathrm{mg} / \mathrm{m}^{2}\right)$ (i.e., CAPOX) every 3 weeks. Oxaliplatin was given intravenously on the first day of each cycle and capecitabine was taken orally for 14 days in 21-day cycles. Before CRS and HIPEC were performed, patients were given a 4-week recovery period after the last cycle of chemotherapy. If the patient had not recovered satisfactorily by this time, recovery could be extended to a maximum of 10 weeks. To be eligible for surgery, patients were not allowed to have leucopenia or thrombocytopenia, and were required to have a WHO performance score of 2 or less. The CRS plus HIPEC procedure followed the protocol described under standard treatment.

CT scans were performed to provide a baseline assessment before systemic treatment, and tumor response was re-evaluated after three and six treatment cycles. These evaluations were done by a radiologist, according to the Response Evaluation Criteria in Solid Tumors (RECIST) criteria [24]. If tumor progression was seen on the follow-up CT, without extra-abdominal or liver metastases, patients went directly for CRS and HIPEC. If the tumor was non-resectable or if extra-abdominal or liver metastases were present, palliative surgery and/or palliative systemic treatment were offered.

\section{Data collection}

Data were recorded for the following variables: primary diagnosis, age, length of hospital stay, PCI, blood loss during surgery, duration of surgery, complications during systemic chemotherapy, complications in the 30 days following CRS and HIPEC, whether the full chemotherapy cycle was completed, disease progression, and survival. Surgical complications were reported according to the Clavien-Dindo classification [25]. Complications were given by system, as follows: cardiovascular complications included arrhythmias and deep vein thrombosis; pulmonary complications included pneumonia, atelectasis, pleural effusion, and pulmonary embolism; gastrointestinal complications included gastroparesis, excessive pain, and gastric retention; mental complications included delirium and excessive fear; and neurological complications included neuropathy and impaired nerve function.

\section{Primary outcome}

To assess the feasibility of neoadjuvant chemotherapy, we evaluated the surgical details, the postoperative complications, and the mortality rates. In the experimental group, this was done by an independent data monitoring committee that was not connected to the study. This comprised an oncology surgeon, a medical oncologist, and an independent statistician. For the historic cohort, all complications were reviewed by the independent team who performed the earlier study [21].

\section{Secondary outcomes}

Secondary outcomes were blood loss, length of surgery, and body mass index at the time of diagnosis (as a surrogate marker of advanced disease status). For the control group, blood loss was only analyzed from 2010 because it was not recorded before that date.

\section{Feasibility}

Neoadjuvant chemotherapy was determined feasible if postoperative complications rates, perioperative blood loss, and length of surgery were comparable between the experimental and the historical control group.

\section{Analysis}

Descriptive analyses of the treatments and outcomes were performed for patients in the experimental group. To assess differences between the experimental and control groups, 95\% confidence intervals around the outcomes in the historical cohort were calculated, and we determined whether the values for the experimental patients were within these confidence limits.

\section{Results}

The baseline characteristics of the 14 patients in the experimental group and the 88 patients in the control group are summarized in Table 1 . Overall, the experimental group was slightly older than the control group and had a slightly higher median body mass index. In the experimental group, peritoneal carcinomatosis was synchronous in 10 patients and metachronous in 4; in the control group, it was synchronous in 66 and metachronous in 22. Figure 1 illustrates the treatment of the patients in the experimental group.

\section{Neoadjuvant chemotherapy}

An overview of the treatment and outcomes is provided for the experimental group in Table 2. Among the 14 patients in the experimental group, 4 required a dose reduction and

Table 1 Patient and disease characteristics

\begin{tabular}{lll}
\hline & $\begin{array}{l}\text { Experimental group } \\
N=14\end{array}$ & Control group $N=88$ \\
\hline Age (median) & $\begin{array}{l}\text { 66.5 years } \\
\text { (range 47-75 years) }\end{array}$ & $\begin{array}{l}\text { 59 years } \\
\text { (range 26-76) }\end{array}$ \\
Gender & Female 42.9\% & Female 51.8\% \\
& Male 57.1\% & Male 48.2\% \\
BMI (median) & 26.4 (range 20.31-35.08) & 23.7 (range 11.47-40.04) \\
Origin of peritoneal & Colorectal 14 & Colorectal 110 \\
carcinomatosis & & \\
\hline BMI body mass index & &
\end{tabular}




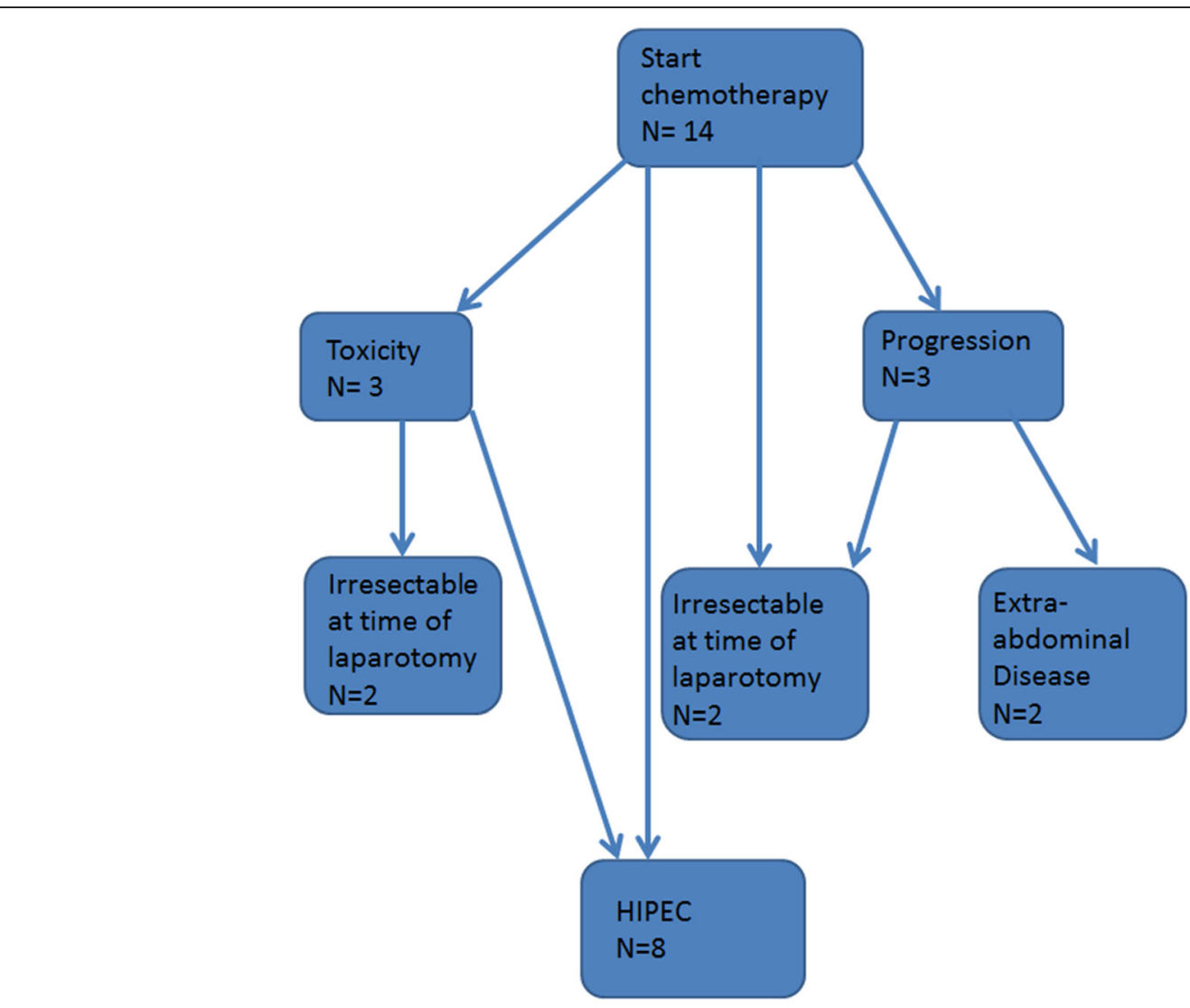

Fig. 1 Flowchart of patients treatment

7 terminated neoadjuvant treatment early (disease progression in 3 patients and toxicity in 4 patients). Two of the patients with disease progression had extra-abdominal disease identified after one and four cycles of chemotherapy, respectively, and neither of these proceeded to CRS and
HIPEC. Finally, one patient had a PCI $>20$ after two cycles of chemotherapy (extensive intra-abdominal disease), one patient had a PCI $>20$ after three cycles of chemotherapy, and one had a PCI $>20$ after six cycles of chemotherapy, with all three being ineligible for CRS and HIPEC.

Table 2 Treatment and outcomes in the experimental group

\begin{tabular}{|c|c|c|c|c|c|c|c|c|}
\hline Patient & Cycles of chemotherapy & Stopped & Reason for stopping & Extra-abdominal metastasis & Laparotomy & $\mathrm{PCl}$ & HIPEC & Current status \\
\hline 1 & 1 & Yes & Toxicity & No & Yes & 15 & Yes, CC-0 & DOD \\
\hline 2 & 6 & No & - & No & Yes & 26 & No & DOD \\
\hline 3 & 6 & No & - & No & Yes & 7 & Yes, CC-0 & AWD \\
\hline 4 & 6 & No & - & No & Yes & 19 & Yes, CC-0 & DOD \\
\hline 5 & 3 & Yes & Progression & No & Yes & 35 & No & DOD \\
\hline 6 & 6 & No & - & No & Yes & 9 & Yes, CC-0 & NED \\
\hline 7 & 6 & No & - & No & Yes & 1 & Yes, CC-0 & NED \\
\hline 8 & 6 & No & - & No & Yes & 4 & Yes, CC-0 & AWD \\
\hline 9 & 3 & Yes & Progression & Yes & No & - & No & AWD \\
\hline 10 & 6 & No & - & No & Yes & 15 & Yes, CC-0 & NED \\
\hline 11 & 2 & Yes & Toxicity & No & Yes & 30 & No & DOD \\
\hline 12 & 6 & Yes & - & No & Yes & 1 & Yes, CC-0 & NED \\
\hline 13 & 1 & Yes & Progression & Yes & No & 17 & No & DOD \\
\hline 14 & 4 & Yes & Toxicity & No & Yes & 18 & No & AWD \\
\hline
\end{tabular}

$D O D$ death of disease, $A W D$ alive with disease, NED no evidence of disease 


\section{The CRS and HIPEC procedure}

Ultimately, eight patients with a median PCI of 15.3 underwent CRS and HIPEC in the experimental group. In the control group, 88 patients underwent CRS and HIPEC before adjuvant chemotherapy. The details of these are compared in Table 3. As shown, median blood loss was broadly comparable between the two groups, but the lengths of surgery and hospital stay were both shorter in the experimental group.

\section{Postoperative complications}

The postoperative complications, and their rates, are summarized in Table 4. In the experimental group, gastrointestinal complications were most common, followed by pulmonary complications or sepsis, with cardiovascular or neurological complications being least common. In the control group, gastrointestinal problems were still most common, followed by nephrological and cardiovascular complications, which were at similar rates, and then pulmonary complications. Neurological complications and sepsis were least common in this group. Although there were no anastomotic leaks in the experimental group, one patient developed an enterocutaneous fistula; by contrast, $8 \%$ of the control group developed anastomotic leakage. There were no treatment-related deaths in either group.

\section{Discussion}

We investigated the feasibility and safety of neoadjuvant chemotherapy before CRS and HIPEC. Our results show that neoadjuvant chemotherapy did not influence either the morbidity or the mortality rate. However, half of the patients did need to stop neoadjuvant chemotherapy early due to disease progression or complications. In a study by Liu et al., it was reported that only $10.7 \%$ of patients needed to stop neoadjuvant therapy [26]. This

Table 3 Comparison of CRS and HIPEC in the experimental and control groups

\begin{tabular}{lll}
\hline & $\begin{array}{l}\text { Experimental group } \\
(N=8)\end{array}$ & $\begin{array}{l}\text { Control group } \\
(N=88)\end{array}$ \\
\hline $\begin{array}{l}\text { Median duration of } \\
\text { hospital stay }\end{array}$ & 15 days (range 2-38) & 15 days (range 4-63) \\
$\begin{array}{l}\text { Median length of } \\
\text { surgery (min) }\end{array}$ & $485(339-617)$ & 502.50 (122-992) \\
$\begin{array}{l}\text { Median blood loss ( } \mathrm{mL}) \\
\text { Resected organs }\end{array}$ & $750(100-2500)$ & $700(100-7000)$ \\
Hemicolectomy & $2 / 8$ & \\
(Sub)total colectomy & $0 / 8$ & $43 / 110$ \\
$\begin{array}{l}\text { Pelvic peritoneum } \\
\text { Splenectomy }\end{array}$ & $6 / 8$ & $10 / 110$ \\
Small bowel resection & $4 / 8$ & $81 / 110$ \\
Cholecystectomy & $2 / 8$ & $31 / 110$ \\
\hline
\end{tabular}

CRS cytoreductive surgery, HIPEC hyperthermic intraperitoneal chemotherapy
Table 4 Complications after CRS and HIPEC

\begin{tabular}{lll}
\hline & Experimental group $N=8$ & Control group $N=88$ \\
\hline Cardiovascular & $1(12.5 \%)$ & $20(18.1 \%)$ \\
Pulmonary & $2(25 \%)$ & $12(10.9 \%)$ \\
Gastrointestinal & $3(37.5 \%)$ & $31(28.2 \%)$ \\
Sepsis/SIRS & $2(25 \%)$ & $9(8.1 \%)$ \\
Mental & $1(12.5 \%)$ & $12(10.9 \%)$ \\
Wound & $2(25 \%)$ & $7(6.4 \%)$ \\
Anastomotic leakage & $0(0 \%)$ & $8(7.2 \%)$ \\
Neurological & $1(12.5 \%)$ & $2(1.8 \%)$ \\
Nephrological & $0(0 \%)$ & $19(17.3 \%)$ \\
\hline
\end{tabular}

CRS cytoreductive surgery, HPEC hyperthermic intraperitoneal chemotherapy

difference may have arisen because the mean number of completed cycles in their study was 2.7, compared with 4.2 in ours. In a study in which FOLFOX (folinic acid, fluorouracil, and oxaliplatin) was used preoperatively, the researchers showed that only $14 \%$ had to terminate chemotherapy early [27]. This difference might be explained by the bigger sample size of the study and the fact that the goal of neo-adjuvant treatment was to make unresectable metastases resectable. If this was not possible, patients did not undergo surgery. However, patients in our study were required to be sufficiently healthy to tolerate CRS and HIPEC, so those with extensive complications were not included.

Three of our patients (21\%) showed tumor progression during systemic chemotherapy, which is consistent with prior research experience. Indeed, studies of patients suffering from liver metastases due to CRC have shown that $11.2 \%(4 / 36)$ or $23 \%(3 / 13)$ had disease progression while receiving neoadjuvant chemotherapy [27, 28]. It can be argued that these patients may miss out on potentially curative surgery if they are selected for neoadjuvant treatment. However, failure of neoadjuvant treatment can be indicative of the fact that a tumor is either not chemosensitive or that the patient is too weak to undergo further treatment. As such, the additional value of CRS and HIPEC is questionable in these patients, and tumor progression during neoadjuvant treatment may be a contraindication to further surgery.

The rate of postoperative complications tends to be high after CRS and HIPEC, with reports giving rates ranging from 23 to $66 \%[2,5,12-15]$. The most frequent complications are small bowel leakage, digestive fistulas, and abdominal sepsis [7, 13, 29]. Earlier studies of neoadjuvant chemotherapy in patients with colorectal liver metastases showed that there was a slight increase in postoperative infections and blood loss with the approach $[16,30]$. In our study, however, the incidence of postoperative complications did not differ between the experimental and control groups. Compared with 
the historic control group, there were more pulmonary ( $25 \%$ vs $11.4 \%)$, sepsis ( $25 \%$ vs $8 \%)$, and neurological (12.5\% vs $1.8 \%)$ complications in the experimental group, and there were fewer cardiovascular complications $(12.5 \%$ vs $27.3 \%$ ) and no renal complications ( $0 \%$ vs $19.3 \%$ ).

To the best of our knowledge, this study is the first prospective study of the feasibility and safety of neoadjuvant chemotherapy before CRS and HIPEC. However, there are some important limitations to this research. Notably, the registration of complications in the historic control group was controlled by a different research team, and as such, was beyond our control. Also, the study design and aim meant that we included few patients from only one center, limiting our ability to generalize the results. Furthermore, this study did not take into account an eventual role of tumor biology or the influence of RAS/RAF mutations on the efficacy of neoadjuvant chemotherapy. Earlier studies have shown that that the reaction to targeted chemotherapy and overall survival might be influenced by these mutations in patients with peritoneal carcinomatosis from colorectal cancer. This should be taken into account when focusing on the efficacy of neoadjuvant chemotherapy in future trials $[31,32]$. Finally, the median age was higher in the experimental group, but this may have had limited relevance because we observed no differences in complication rates. In the future, a prospective randomized controlled trial could answer the question whether neoadjuvant chemotherapy prior to CRS and HIPEC is effective in preventing hematogenous and lymphogenous metastases.

\section{Conclusion}

In conclusion, postoperative complication rates, perioperative blood loss, and length of surgery are not increased by giving neoadjuvant treatment before CRS and HIPEC. Therefore, it can be considered feasible and safe to perform further study on the effects of neoadjuvant chemotherapy before CRS and HIPEC. In the future, we aim to investigate the efficacy of neoadjuvant chemotherapy in a multicenter trial, specifically assessing not only its effect on survival but also whether responsiveness to it could serve as a selection criterion for CRS and HIPEC.

\section{Abbreviations}

CRS: Cytoreductive surgery; CT: Computed tomography; HIPEC: Hyperthermic intraperitoneal chemotherapy; PCI: Peritoneal cancer index; RECIST: Response evaluation criteria in solid tumors; UMCG: University Medical Center of Groningen; WHO: World Health Organization

\section{Acknowledgements \\ None.}

\section{Funding}

We have no financial disclosures

\section{Availability of data and materials}

The dataset generated during the study are not publicly available, but might be available from the corresponding author on reasonable request.

\section{Authors' contributions}

Study concepts: PHJH, AKR, DJAG, RJG, LBB, BLL. Study design: PHJH, AKR, DJAG, RJG, GHB, LBB, BLL. Data acquisition: PHJH, BLL. Quality control of data and algorithms: PHJH, BIL. Data analysis and interpretiation: ML, GHB. Statistical analysis: ML, GHB, PHJH. Manuscript preparation: ML, GHB, PHJH. Manuscript editing: ML, GHB, BLL. Manuscript review: DJAG, GHB, BLL. All authors read and approved the final manuscript.

\section{Ethics approval and consent to participate}

The study was conducted in accordance with the Declaration of Helsinki and approved by the Medical Ethics Committee of the UMCG and was registered in the Dutch trial registry (NTR 3905, registered on 20th march, 2013, http:// www.trialregister.nl/trialreg/admin/rctview.asp?TC=3905).

\section{Consent for publication}

All patients provided informed consent to be included in the study. All authors are informed of submission of the manuscript and give their consent to publication

\section{Competing interests}

The authors declare that they have no competing interests.

\section{Publisher's Note}

Springer Nature remains neutral with regard to jurisdictional claims in published maps and institutional affiliations.

\section{Author details}

'Department of Surgery, University of Groningen, University Medical Center Groningen, Hanzeplein 1, 9713GZ, Groningen, The Netherlands. ${ }^{2}$ Department of Medical Oncology, University of Groningen, University Medical Center Groningen, Hanzeplein 1, 9713GZ, Groningen, The Netherlands. ${ }^{3}$ Department of Epidemiology, University of Groningen, University Medical Center Groningen, Hanzeplein 1, 9713GZ, Groningen, The Netherlands.

Received: 8 October 2018 Accepted: 27 December 2018

Published online: 11 January 2019

\section{References}

1. Cao C, Yan TD, Black D, Morris DL. A systematic review and meta-analysis of cytoreductive surgery with perioperative intraperitoneal chemotherapy for peritoneal carcinomatosis of colorectal origin. Ann Surg Oncol. 2009 Aug; 16(8):2152-65

2. Gomez Portilla A, Barrios P, Rufian S, Camps B, Bretcha P, Gonzalez Bayon L, et al. Management of peritoneal surface malignancy with cytoreductive surgery and perioperative intraperitoneal chemotherapy. Eur J Surg Oncol. 2006 Aug;32(6):628-31.

3. Jayne DG, Fook S, Loi C, Seow-Choen F. Peritoneal carcinomatosis from colorectal cancer. Br J Surg. 2002 Dec;89(12):1545-50.

4. Mahteme H, Hansson J, Berglund A, Pahlman L, Glimelius B, Nygren P, et al. Improved survival in patients with peritoneal metastases from colorectal cancer: a preliminary study. Br J Cancer. 2004 Jan 26;90(2):403-7.

5. de Gramont A, Figer A, Seymour M, Homerin M, Hmissi A, Cassidy J, et al. Leucovorin and fluorouracil with or without oxaliplatin as first-line treatment in advanced colorectal cancer. J Clin Oncol. 2000 Aug;18(16): 2938-47.

6. Kuramochi H, Ando M, Itabashi M, Nakajima G, Kawakami K, Hamano M, et al. Phase II study of bevacizumab and irinotecan as second-line therapy for patients with metastatic colorectal cancer previously treated with fluoropyrimidines, oxaliplatin, and bevacizumab. Cancer Chemother Pharmacol. 2017 Mar;79(3):579-85.

7. Glehen $\mathrm{O}$, Kwiatkowski F, Sugarbaker PH, Elias D, Levine EA, De Simone M, et al. Cytoreductive surgery combined with perioperative intraperitoneal chemotherapy for the management of peritoneal carcinomatosis from colorectal cancer: a multi-institutional study. J Clin Oncol. 2004 Aug 15; 22(16):3284-92.

8. Elias D, Delperro JR, Sideris L, Benhamou E, Pocard M, Baton O, et al. Treatment of peritoneal carcinomatosis from colorectal cancer: impact of complete cytoreductive surgery and difficulties in conducting randomized trials. Ann Surg Oncol. 2004 May; 11(5):518-21.

9. Ung L, Chua TC, David LM. Peritoneal metastases of lower gastrointestinal tract origin: a comparative study of patient outcomes following 
cytoreduction and intraperitoneal chemotherapy. J Cancer Res Clin Oncol. 2013 Nov;139(11):1899-908.

10. Elias D, Lefevre JH, Chevalier J, Brouquet A, Marchal F, Classe JM, et al. Complete cytoreductive surgery plus intraperitoneal chemohyperthermia with oxaliplatin for peritoneal carcinomatosis of colorectal origin. J Clin Oncol. 2009 Feb 10;27(5):681-5

11. Esquivel J, Lowy AM, Markman M, Chua T, Pelz J, Baratti D, et al. The American Society of Peritoneal Surface Malignancies (ASPSM) multiinstitution evaluation of the peritoneal surface disease severity score (PSDSS) in 1,013 patients with colorectal cancer with peritoneal carcinomatosis. Ann Surg Oncol. 2014 Dec;21(13):4195-201.

12. van Leeuwen BL, Graf W, Pahlman L, Mahteme H. Swedish experience with peritonectomy and HIPEC. HIPEC in peritoneal carcinomatosis. Ann Surg Oncol. 2008 Mar; 15(3):745-53.

13. Verwaal VJ, van Ruth $S$, de Bree $E$, van Sloothen GW, van Tinteren $H$, Boot $H$, et al. Randomized trial of cytoreduction and hyperthermic intraperitoneal chemotherapy versus systemic chemotherapy and palliative surgery in patients with peritoneal carcinomatosis of colorectal cancer. J Clin Oncol. 2003 Oct 15;21(20):3737-43.

14. Robella M, Vaira M, Cinquegrana A, Borsano A, DE Simone M. Cytoreductive surgery and hyperthermic intraperitoneal chemotherapy: risk factors for morbidity and postoperative outcome. Minerva Chir. 2018.

15. van Eden WJ, Kok NFM, Woensdregt K, Huitema ADR, Boot H, Aalbers AGJ. Safety of intraperitoneal Mitomycin C versus intraperitoneal oxaliplatin in patients with peritoneal carcinomatosis of colorectal cancer undergoing cytoreductive surgery and HIPEC. Eur J Surg Oncol. 2018 Feb;44(2):220-7.

16. Shankar A, Leonard P, Renaut AJ, Lederman J, Lees WR, Gillams AR, et al. Neo-adjuvant therapy improves resectability rates for colorectal liver metastases. Ann R Coll Surg Engl. 2001 Mar;83(2):85-8.

17. Karanjia ND, Lordan JT, Fawcett WJ, Quiney N, Worthington TR. Survival and recurrence after neo-adjuvant chemotherapy and liver resection for colorectal metastases: a ten year study. Eur J Surg Oncol. 2009 Aug;35(8):838-43.

18. Passot G, Vaudoyer $D$, Cotte E, You B, Isaac $S$, Noel Gilly F, et al. Progression following neoadjuvant systemic chemotherapy may not be a contraindication to a curative approach for colorectal carcinomatosis. Ann Surg. 2012 Jul;256(1):125-9.

19. van Dijk TH, Tamas K, Beukema JC, Beets GL, Gelderblom AJ, de Jong KP, et al. Evaluation of short-course radiotherapy followed by neoadjuvant bevacizumab, capecitabine, and oxaliplatin and subsequent radical surgica treatment in primary stage IV rectal cancer. Ann Oncol. 2013 Jul;24(7):1762-9.

20. Common Terminology Criteria for Adverse Events (CTCAE) Version 4.0 Published: May 28, 2009 (v4.03: June 14, 2010) U.S. Department Of Health And Human Services.

21. Harlaar NJ, Koller M, de Jongh SJ, van Leeuwen BL, Hemmer PH, Kruijff S, et al. Molecular fluorescence-guided surgery of peritoneal carcinomatosis of colorectal origin: a single-centre feasibility study. Lancet Gastroenterol Hepatol. 2016 Dec; 1(4):283-90.

22. Klaver CE, Musters GD, Bemelman WA, Punt CJ, Verwaal VJ, Dijkgraaf MG, et al. Adjuvant hyperthermic intraperitoneal chemotherapy (HIPEC) in patients with colon cancer at high risk of peritoneal carcinomatosis; the COLOPEC randomized multicentre trial. BMC Cancer. 2015 May 24;15:7.

23. Esquivel J, Elias D, Baratti D, Kusamura S, Deraco M. Consensus statement on the loco regional treatment of colorectal cancer with peritoneal dissemination. J Surg Oncol. 2008 Sep 15;98(4):263-7.

24. Seymour L, Bogaerts J, Perrone A, Ford R, Schwartz LH, Mandrekar S, et al. iRECIST: guidelines for response criteria for use in trials testing immunotherapeutics. Lancet Oncol. 2017 Mar;18(3):e152.

25. Clavien PA, Barkun J, de Oliveira ML, Vauthey JN, Dindo D, Schulick RD, et al. The Clavien-Dindo classification of surgical complications: five-year experience. Ann Surg. 2009 Aug;250(2):187-96.

26. Liu F, Yang L, Wu Y, Li C, Zhao J, Keranmu A, et al. CapOX as neoadjuvant chemotherapy for locally advanced operable colon cancer patients: a prospective single-arm phase II trial. Chin J Cancer Res. 2016 Dec;28(6):589-97.

27. Takahashi T, Shibata Y, Tojima Y, Tsuboi K, Sakamoto E, Kunieda K, et al. Multicenter phase II study of modified FOLFOX6 as neoadjuvant chemotherapy for patients with unresectable liver-only metastases from colorectal cancer in Japan: ROOF study. Int J Clin Oncol. 2013 Apr;18(2):335-42.

28. Takatsuki M, Tokunaga S, Uchida S, Sakoda M, Shirabe K, Beppu T, et al. Evaluation of resectability after neoadjuvant chemotherapy for primary nonresectable colorectal liver metastases: a multicenter study. Eur J Surg Oncol. 2016 Feb;42(2):184-9.
29. Simkens GA, van Oudheusden TR, Luyer MD, Nienhuijs SW, Nieuwenhuijzen GA, Rutten HJ, et al. Serious postoperative complications affect early recurrence after cytoreductive surgery and HIPEC for colorectal peritoneal Carcinomatosis. Ann Surg Oncol. 2015 Aug;22(8):2656-62.

30. Benoist S, Nordlinger B. The role of preoperative chemotherapy in patients with resectable colorectal liver metastases. Ann Surg Oncol. 2009 Sep;16(9): 2385-90.

31. Schneider MA, Eden J, Pache B, Laminger F, Lopez-Lopez V, Steffen T, et al. Mutations of RAS/RAF proto-oncogenes impair survival after cytoreductive surgery and HIPEC for peritoneal metastasis of colorectal origin. Ann Surg. 2018 Nov;268(5):845-53.

32. Van Cutsem E, Kohne CH, Hitre E, Zaluski J, Chang Chien CR, Makhson A, et al. Cetuximab and chemotherapy as initial treatment for metastatic colorectal cancer. N Engl J Med. 2009 Apr 2;360(14):1408-17.

\section{Ready to submit your research? Choose BMC and benefit from:}

- fast, convenient online submission

- thorough peer review by experienced researchers in your field

- rapid publication on acceptance

- support for research data, including large and complex data types

- gold Open Access which fosters wider collaboration and increased citations

- maximum visibility for your research: over $100 \mathrm{M}$ website views per year

At BMC, research is always in progress.

Learn more biomedcentral.com/submissions 